\title{
Relatively Financing Efficiency in Public Private Partnership: an Empirical Evidence from China
}

\author{
Wang Chang Feng ${ }^{1}$, Qiu Yixin ${ }^{1}$, Umair Akram ${ }^{1 *}$ and Shahid Rasheed ${ }^{1}$ \\ ${ }^{1}$ School of Economics and Management, Beijing University of Posts and \\ Telecommunications, Beijing 100876, China \\ ${ }^{1}$ wangcf@bupt.edu.cn, ${ }^{2}$ qisme_q@163.com, ${ }^{3 *}$ leo_umairinfo@yahoo.com, \\ ${ }^{4}$ shahidrasheed@outlook.com
}

\begin{abstract}
Public-Private-Partnership (PPP) mode has been greatly recommended by Chinese government as a new financing mode; however, some other dimension should be explored on its efficiency of financing which is a critical significance in PPP application. This study aims to provide an avenue to research and evaluate the relative efficiency of financing of PPP projects empirically. A VRS model is established for computing the relative efficiency of financing in PPP projects which incorporates qualitative information and quantitative analysis. The specific model is adopted to analyze the application of PPP mode in China from two aspects (a) does PPP mode plays a positive role in financing of projects in China, and $(b)$ where China stands in application of PPP mode all over the world. The results show that (a) the application of PPP model commendably improves the efficiency of Chinese construction projects, and $(b)$ at present the efficiency of financing in Chinese PPP projects is at a relatively higher level as compared to the other countries in the world. This model helps to provide measurable basis to have a deeper understanding of PPP and gives empirical evidence for stakeholders in PPP project to choose an optimal scheme and knowing their relative level better.
\end{abstract}

Keywords: public-private-partnership (PPP); VRS model; efficiency of financing; relative effectiveness

\section{Introduction}

Around the world, public-private partnership (PPP) has become an increasingly popular means for procuring public services and infrastructure [1]. Therefore, a deeper understanding and more efficient application of PPP is of particular importance. The public-private partnership (PPP) is a type of new model for project financing, which establishes cooperation between the public sector (essentially the government) and the private sector in a certain way to complete construction, operation, and management of municipal infrastructure. IMF outlines PPP as an arrangement in which the private sector participates in the supply of assets and services traditionally provided by the government [2]. In the definition from United Nation, Public-Private Partnerships (PPP) aim at financing, designing, implementing and operating public sector facilities and services, which include three key characteristics: long-term (sometimes up to 30 years) service provisions, the transfer of risk to the private sector and different forms of long-term contracts drawn up between legal entities and public authorities [3]. It is a win-win option that enables the government to secure infrastructure without immediately and largely raising funds meanwhile private sector benefits from investment. This is a central intention for the ongoing growth of PPP, in another word, known as 'project finance', which contribute to construction as a financing technique. 
PPP activities are highly reliant on project finance-related contract structures [4]. Project finance plays an essential role in life cycle management of PPP projects, which means a method of raising long-term debt financing for major projects. It is a form of 'financial engineering', based on lending against the cash flow generated by the project, and depends on a detailed evaluation of a project's construction, operating and revenue risks, and their allocation between investors, lenders, and other parties through contractual and other arrangements [5]. According to Finnerty (2007) project finance is "the raising of funds on a limited-recourse or non-recourse basis to finance an economically separable capital investment project in which the providers of the funds look primarily to the cash flow from the project as the source of funds to service their equity invested in the project" [6]. Some other definitions have been put forward. Gatti (2013) further detailed the types of financial instruments for stakeholders to employ in a transaction [7]. In this specific financing technique, the participation of private sector achieves a better efficiency of investment and finance in PPP projects; it makes for the value of money basis. Finance is a key part of projects, especially for PPP projects, while the efficiency of financing is an even more vital indicator and target in finance which run out the whole life circle. Under such consideration, the study of the efficiency of financing in PPP projects is particularly necessary. As Rogério Studart states in his study, efficiency is closely related to a more liberalized, deregulated financial system [8].

Advantages of PPP are always described in literatures, particularly its effect on efficient utilization of money. G.W.E.B. van Herpen summarizes it in seven main points; they are the value of money, cost efficiencies, time-to-delivery savings, reduction on the public treasury, improved response to market forces, broad support and improved cost calculations [9]. The ministry of Singapore sort benefits into 3 categories: for the public sector (private sector expertise and competitive advantage, cost efficiency through lifecycle optimization, optimal sharing of risks), for the private sector (offers more business opportunities, designing and delivering innovative solutions, opportunity to spur their development in), and for members of the public (meet their needs effectively and efficiently, meet needs at the best value for money) [10]. The value of money and the cost efficiency are commonly addressed by its referrers and users. However, most of these conclusions are subjective judgments, but lack of objective and measurable demonstrations and reality-based researches to support these items. For this purpose, efforts need to be paid for making a comparison between PPP projects and non-PPP projects all around to explore the effects and visualized improvement.

Considering all mentioned positive impacts of PPP in financing and construction, in the late 20th century, the Chinese government launched pilot programs and extended PPP mode to several industries, many of them went successfully. In 2015, PPP mode was greatly recommended by Chinese government whereby 1043 PPP projects with a total investment of 1.97 trillion Chinese Yuan were officially issued. While PPP is a pattern espoused from abroad, whether it is applicable to a socialist market economy like China or not remains a question. Does the financing in PPP projects perform efficiently as compared to financing in non-PPP projects? Where does China stand in terms of efficiency of financing in PPP mode when compared with the other countries? All these questions are worth exploring while broadening the scopes of PPP applications.

In order to seek a solution to all above concerns, the current study aims to provide an approach to explore the relative efficiency of financing in PPP projects. In order to learn the effectiveness of financing running in PPP application, the main influential factors for the relative efficiency of financing in PPP mode should be discussed, which should be probed from the perspective of projects itself, and then establish a proper model to quantify the results. Further, the model can be applied in studying the application and effectiveness of PPP mode in China. This study is able to extend a measurable methodology to explore relative efficiency of financing of objective PPP project by comparing it with the others. Additionally, the impact of PPP model exerts to the 
efficiency of financing in projects can be evaluated, and offers a glimpse to know the relative effectiveness of PPP mode application. Since the study of financing in PPP projects itself, a multidisciplinary undertaking, it is hoped that the specific efficiency of financing evaluation model of PPP projects in this study will provide a practical point of reference toward the decision making and assessment of PPP projects.

\section{Literature Review}

"Efficiency of financing" was put forward for the first time in the end of 20th century by Zeng Kanglin (1993), he raised seven impact factors (restrict of interest mechanism, risk of investment, sensitivity and validity of information, development of market economics, effect of monetary policy, stability of object and selection of field) that should be covered in efficiency of financing. [11]. The importance of efficiency of finance is still proposed and investigated by a number of contemporary scholars. Farrah Wahieda Kasiran (2016) states briefly that working capital management is one of the most vital segments in firm's financing decisions as an important stimulus towards firm's performance, and analyzes the efficiency of working capital management in the selected small medium enterprise companies in Malaysia [12]. The inefficiency of the working capital management has a negative impact on the stockholders' value [13].

Meanwhile, the importance of combination between theoretical research of efficiency of financing and practical operational assessment had been ever more recognized. According to the Liu Lichang (2004), Gao Shan (2010) and Nikolaus Ederer (2015), they are experts in the efficiency of financing field, they apply different empirical methodologies to evaluate and analyze. Liu Lichang (2004) studied the relative efficiency of financing of 47 companies which had their initial public offering in 1998 in Shanghai [14]. The CRS model of data envelopment analysis (DEA) helped to give a comprehensive evaluation, research results showed that the overall efficiency of financing of Chinese listed companies was relatively low. DEA also played a part in Gao Shan's study (2010) who researched the relative efficiency of financing of 65 listed small technology-based business in China. In this study, a variant model of DEA i.e. VRS model that caters to the real situation better, was used. The study clarified that the relative efficiency of financing of listed small technology-based business in China is relatively inefficient [15]. Nikolaus Ederer (2015) evaluated capital and operating cost efficiency of offshore wind farms by adopted DEA model as well [16].

In recent years, with the pilot application and generalization of PPP mode, this promising mechanism has been widely employed which leads to the popularity of financing of efficiency in this new project financing model among scholars in PPP field. Sun Fengxuan (2006) presented a comprehensive index system to evaluate the efficiency of financing of urban rail transit projects in China with grey fuzzy theory. By utilizing this system, he made a comparison among three financing schemes: government investment, BOT, and PPP. The result shows that PPP mode is the most efficient mode in financing [17]. Liu Quanzhi (2012) adopted CRS model of DEA method in her study and systematically calculated the relative efficiency of financing of a crural water conservancy facility. It illustrated that the construction of rural water conservancy facility in Liaoning province before the application of PPP mode is relatively backward [18]. Peter F. Wanke (2015) employee two-stage DEA analysis to explore scale efficiency in Brazilian PPP ports projects. Results indicate a strong positive impact of PPP mode on port scale efficiency, corroborating their impacts in relation to the most productive scale size [19].

On the basis of all the above-mentioned scholars, we catch a point that data envelopment analysis method (DEA) is widely applicable in the evaluation of the relative efficiency of financing. Due to its multiple indexes system, availability of results without defining the computing formula of all the impact factors, and automatically weight assigned on the aspect of optimal decision-making unit. Although earlier studies include various methodologies to evaluate the relative efficiency of financing, only a few have 
considered choosing the more practical model-VRS model in DEA method to study the relative effectiveness of PPP mode in the efficiency of financing field. In addition, while evaluating the relative efficiency of financing of PPP projects, the previous calculation index for the efficiency of financing of companies have not gone through corresponding changes, therefore a tailored model which is in line with the actual situation and the characteristics of PPP projects is absent. In view of the above, this paper aims to study from the angle of PPP projects itself and to design and establish a more realistic model to evaluate the efficiency of finance in PPP projects. VRS model in DEA method can play an important role to achieve this goal.

\section{Research Methodology}

\subsection{Research Methodology for Relative Efficiency of Financing in PPP Projects}

Data Envelopment Analysis (DEA) method is a quantitative analysis method which is available for analyzing the devotion and outputs with multi-input and multi-output indexes. It evaluates the relative efficiency of a comparable decision-making unit by using the method of linear programming [20].

The famous operations researcher-Charnes first proposed CRS model of DEA in 1978. It is designed on the basis of constant returns to scale (CRS) hypothesis for evaluating the production efficiency. In the operational procedure of DEA, some of the decision-making units generate the production frontier whose constitution of input and output is most efficient. These units make up an effective decision-making unit set with relative efficiency which equals 1 ; the relative efficiency of the other decision-making units with values from 0 to 1 (without including 0 and 1). This system well fit the practical need of relative effectiveness evaluation for different units when they share the same input and output index. Toshiyuki Sueyoshi (2015) make a comparison among U.S. energy industry sectors by adopting DEA method [21], Bing Wu (2015) use DEA to assess the effectiveness of maritime safety control in different navigation zones in Yangtze River [22]. While the constant returns to scale hypothesis signifies that the scale of output should be expanded in the same proportion with the input increase for every decisionmaking unit. In reality, it is very hard to match the actual production situation with this restrictive assumption because some restraints such as market competitions and the law of diminishing marginal returns always exist. This contradiction neglects the influence of the scale factor, as well as bears a negative effect on the efficiency evaluation. To address this problem, scholars like Banker proposed an improved model for Data Envelopment Analysis method in 1984, which allows for the evaluation of efficiency in variable returns to scale (VRS) circumstance [23]. By adopting the improved VRS model, it is possible to evaluate the technical efficiency separately, without the influence of scale efficiency. Combined with CRS model, a separate evaluation of scale efficiency is available as well. Ravi Kumar Jain (2015) employees VRS model to calculate technical and scale efficiencies of all airlines across service type, size and ownership structures operating in India during 2006-2010 [24]. This model has been employed in this research.

\subsection{The Economic Significance of the Efficiency of Financing in VRS Model}

The efficiency of financing made by improved VRS model is a pure technical efficiency without scale influence; we note it as $\theta_{P E}$. The efficiency of financing made by CRS model is a technical efficiency which involves the influence of scale; we note it as $\theta$. When we use the VRS model in combination with the CRS model, we can resolve a scale efficiency index; going on similarly trends we note it as $\theta_{S E}$. According to Farrell's research (1957) in relative efficiency, there is a relationship among pure technical efficiency, technical efficiency, and scale efficiency as follow [25]: 
All of these three efficiency indexes are used to evaluate the relative effectiveness.

In the efficiency of financing evaluation model, when $\theta_{P E}$ and $\theta_{S E}$ equals 1 at the same time, it means that among this decision making units set, the pure technical efficiency of financing and scale efficiency of financing in the evaluated decision making unit achieve the optimal state; the closer to 1 is the value of $\theta_{P E}$ and $\theta_{S E}$, the more effective is the pure technical efficiency of financing and scale efficiency of financing in the evaluated decision making unit; meanwhile, if $\theta_{P E}<1$ or $\theta_{S E}<1$, it respectively expresses that compared with the other units, the pure technical efficiency of financing or the scale efficiency of financing in the evaluated decision making unit is ineffective. It is necessary to point out that the ineffective of scale efficiency of financing may result from the oversize or undersize of financing scale, and we should judge it by the model results.

In summary, pure technical efficiency of financing $\theta_{P E}$ in VRS model shows the allocation, management, and utilization level of funds in the process of financing, which is mainly determined by financing form and management system. Scale efficiency of financing indicates the reasonableness of financing scale and it is decided by construction scale and financial size.

\subsection{The Applicability of VRS in Proposed Model}

According to the Peter F. Wanke (2015), Liu Quanzhi (2012) and Gao Shan (2010) DEA method has been extensively applied for the efficiency of financing evaluation. In this study, the improved model (VRS model) of DEA method is selected to study the relative efficiency of financing in PPP projects for the following reasons and advantages.

DEA method is available for relative efficiency evaluation with multi-input and multioutput index in PPP projects. PPP means the project involves multi-partners' corporation; multiple partners devote and participate in, at the same time and each of partners pursues their own interests, which decides the evaluation process is necessary to be a multi-input and multi-output system. Therefore, if we want to establish a comprehensive system involves multiple indexes for making a relative comparison and evaluation of the efficiency of financing among different PPP projects, DEA method provides a distinct advantage here.

By adopting DEA method, indexes can process automatically without dimensionless processing, and obtain the weight value of indexes without a subjective assignment. In DEA method, the optimal efficiency of decision-making unit is dimension-independent. Because DEA method does not synthesize data straight, the definition of function expression among different indexes is not necessary as well. The optimal weights will be calculated according to actual input and output in the model. Firstly, it avoids the subjective impact caused by artificial weight assignment; secondly, it averts the deviation resulted from the application of different non-dimensional ways.

The assumption of VRS model coincides with the practical construction status in PPP projects. During the implementation of PPP or the other construction projects restricted by factors like technique, market competition, and the environment limitation, it is almost impossible to achieve the constant returns to scale hypothesis. So the VRS model, which is built on the basis of variable returns to scale hypothesis, shows a better accordance with the study background of the relative efficiency of financing in PPP projects. It, therefore, helps in getting objective and scientific evaluation results.

We can make optimization analysis for the evaluated PPP projects according to the VRS model results. In the calculation process of DEA method, an efficient frontier hyperplane will be formed by the efficient decision-making unit, and it will be taken as a criterion to evaluate the relative effectiveness of the other decision-making unit. Thus, 
when we compare the inefficient decision-making unit with the efficient frontier hyperplane and obtain the slack variable, we can capture the specific indexes that need to be improved, as well as its adjusting extent. It offers a reasonable and operable optimization direction and goals for PPP projects.

\section{Establishing the model}

\subsection{Selection of Evaluation Indexes in VRS Model}

To have a correct use of the DEA method, it is a key step to select input and output indexes properly in the process of relative effectiveness evaluation [9]. According to the definition of PPP project financing in this study, the efficiency of financing involves two major areas: raising funds at low cost and using funds efficiently. In addition, considering franchise and public service of public infrastructure are two characteristics in PPP project, in this paper, we design the ratio of capital funds, the construction time and the franchise as input indexes; select the social influence and turnover ratio of total capital as output indexes.

a. Ratio of capital funds $\left(\mathrm{X}_{1}\right)$ :

The ratio of capital funds in PPP projects is refered to the percentage of the capital amount contributed by partners in the total investment. To some extent, it represents funding status in PPP projects, as well as the financing ability with limited capital. The formula is given in < Engineering Economics > as follow [26]:

$$
\mathrm{X}_{1}=\frac{\text { capital invested by partners }}{\text { total construction cost of PPP projects }}
$$

b. Construction time $\left(\mathrm{X}_{2}\right)$ :

The time value of money is an important factor that affects the efficiency of financing. Therefore, considering the relation between construction time and efficiency of PPP projects, and in addition, fully take the financing cost caused by the time value of money into account, we select the time value of money as an input index for evaluating the relative effectiveness of efficiency of financing in PPP projects.

c. Franchise rights $\left(\mathrm{X}_{3}\right)$ :

In PPP financing model, the public sector always privileges the franchise of public infrastructure to co-enterprises for a certain length of time, in order to attract social enterprises to participate in constructing public infrastructure together. The public infrastructure is then financed, constructed, operated and managed by a special purpose company consist of the public sector and the social enterprise. Thus, the franchise is a characteristic input for PPP projects [12]. The present value method which is commonly used in intangible assets appraisal in enterprises can be applicable to the value assessment of franchise in PPP projects [13]. The general calculation formula is as follows:

$\mathrm{X}_{3}=\sum_{t=1}^{m} \frac{B_{t}}{(1+i)^{t}}$

$\mathrm{X}_{3}$ : asset valuation of evaluated franchise rights,

$B_{t}$ : the excess earnings of the asset in the $t_{\text {th year, }}$

$m$ : authorized operating period of franchise rights,

$i$ : appropriate discount rates.

d. Social influence $\left(\mathrm{Y}_{1}\right)$ : 
Public infrastructure includes all the facilities that provide basic public service to social production and people's livelihood. Thus the social influence is an important criterion to appraise the output value of public infrastructure constructed by PPP mode. In this study, the number of service users $\left(\mu_{1}\right)$ and social concern $\left(\mu_{2}\right)$ these two aspects are combined to quantitatively analyze the social influence caused by PPP projects. The number of service users means visitors or the people been served every year of each decision while making unit project; social concern index is quantitated according to the related news website, both in English and Chinese. The maximum method is adopted to nondimensionalize these two indexes, for solving the unanimous measurement of different dimensions of people and website. Their summation is the value of social influence for each decision-making unit project.

$\mathrm{Y}_{1 j}=\mu_{1}+\mu_{2}=\frac{U_{j}}{\max _{1 \leq j \leq n} U_{j}}+\frac{W_{j}}{\max _{1 \leq j \leq n} W_{j}}$

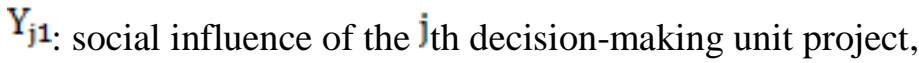

$\mathrm{U}_{\mathrm{j}}$ : service users of the $\mathrm{j}_{\text {th }}$ decision-making unit project,

$W_{\mathrm{j}}$ : related news website both in English and Chinese of the $j_{\text {th }}$ decision-making unit project,

$\mathrm{n}$ : the number of decision-making unit projects.

e. Turnover ratio of total capital $\left(\mathrm{Y}_{2}\right)$ :

Turnover ratio of total capital can be used in the evaluation of management quality and utilization efficiency of total capital in projects. The bigger is the value of turnover ratio, the faster is the total capital turnover. It reflects operational ability and capital utilization in each project and is given by the following equation 5 :

$\mathrm{Y}_{2}=\frac{\text { net operating income }}{\text { average total asset }}$

According to the selected indicators, a DEA model for evaluating the relative effectiveness of efficiency of financing in PPP projects is formed as showed in Figure 1.

\begin{tabular}{|c|c|c|c|c|c|c|}
\hline Input indexes & 1 & $\cdots$ & j & $\cdots$ & $\mathrm{n}$ & \multirow{2}{*}{$\mathrm{DMU}_{\mathrm{j}}$} \\
\hline Ratio of capital funds $\rightarrow$ & $\mathrm{x}_{11}$ & $\cdots$ & $\mathrm{x}_{1 \mathrm{j}}$ & $\cdots$ & $\mathrm{x}_{\mathrm{nn}}$ & \\
\hline Construction time $\rightarrow$ & $\mathrm{x}_{21}$ & $\cdots$ & $x_{2 j}$ & $\cdots$ & $\mathrm{x}_{2 \mathrm{n}}$ & \\
\hline Franchise rights $\rightarrow$ & $\mathrm{x}_{31}$ & $\cdots$ & $\mathrm{x}_{3 \mathrm{j}}$ & $\cdots$ & $\mathrm{x}_{3 \mathrm{n}}$ & output indexes \\
\hline & $\mathrm{y}_{11}$ & $\cdots$ & $y_{1 j}$ & $\cdots$ & $\mathrm{y}_{1 \mathrm{n}}$ & $\rightarrow$ social influence \\
\hline & $\mathrm{y}_{21}$ & $\cdots$ & $y_{2 j}$ & $\cdots$ & $y_{2 n}$ & $\rightarrow$ turnover ratio of total capital \\
\hline
\end{tabular}

Figure 1. DEA Model for the Relative Efficiency of Financing in PPP Projects

\subsection{The VRS Model for Evaluating the Relative Efficiency of Financing in PPP Projects}

In DEA method, the improved VRS model changes the hypothesis condition of constant returns to scale in former model, which is hard to meet, into variable returns to scale; its concrete manifestations is the addition of a $\sum \lambda_{n}=1$ limitation to $C^{2} R$ model on the basis of former dual programming. The calculating model for estimating the relative effectiveness of efficiency of financing in PPP projects is as equation 6: 


$$
\begin{gathered}
\min \left[\theta-\varepsilon\left(\sum_{k=1}^{K} s^{-}+\sum_{l=1}^{L} s^{+}\right)\right] \\
\text {s.t. }\left\{\begin{array}{l}
\sum_{j=1}^{n} \mathrm{x}_{k j} \lambda_{j}+\mathrm{s}^{-}=\theta \mathrm{x}_{\mathrm{k} 0}, \mathrm{k}=1,2,3 \\
\sum_{j=1}^{n} \mathrm{y}_{l j} \lambda_{j}-\mathrm{s}^{+}=\mathrm{y}_{10}, 1=1,2 \\
\sum_{j=1}^{n} \lambda_{j}=1 \\
s^{-}, \mathrm{s}^{+}, \lambda_{j} \geq 0, j=1,2, \ldots, n
\end{array}\right.
\end{gathered}
$$

After we put all the indexes involved in the efficiency of financing of PPP projects, software DEAP2.1 helps to solve numerical calculation. Dan Qi (2012) employee the same software to solve the linear programming of efficiency assessment model which is built based on DEA method [27]. The value of ${ }^{\theta}$ that we obtain in VRS model is the pure technical efficiency $\theta_{P E}$, which shows the relative efficiency in fundraising scheme and financing technique for each specific PPP project. The value of $s^{+}$and $S^{-}$we get from the model are the slack variable and the residual variable respectively. By analyzing them, we can see the redundancy status in each project and design optimized and quantitative scheme for concrete indexes.

\section{Relative Efficiency of Financing of PPP Projects in China- a Case Study}

\subsection{Relative Efficiency of Financing Evaluation for PPP Projects in China Compared with Non-PPP Project}

This study offers a model to study PPP mode which is introduced as a new financing mode in China. Here we combine cases for discussing whether PPP mode makes a substantial increase in efficiency of financing in China. Based on the important rule of thumb put forward by Banker: the number of decision-making units should not be less than twice number of input and output indicators, otherwise the ability to distinguish efficiency will decline [10], this case study choose four typical PPP projects and six nonPPP projects from large Chinese constructions of 21st century which share the similar scale and similar age to make up decision-making unit set. After collecting all the related data for input and output indexes in each decision-making unit project, we solve linear programming problem in VSR model by using Deap2.1 software, and thus pure technical efficiency of financing $\theta_{P E}$, scale efficiency of financing $\theta_{S E}$, technical efficiency of financing $\theta$ and redundancy of input and output is obtained. The evaluation results are listed in table 1. 
Table 1. The Relative Efficiency of Financing Status of Projects in China

\begin{tabular}{clccc}
\hline project name & $\begin{array}{c}\text { pure } \\
\text { technical } \\
\text { efficiency of } \\
\text { financing }\end{array}$ & $\begin{array}{c}\text { scale } \\
\text { efficiency } \\
\text { of } \\
\text { financing }\end{array}$ & $\begin{array}{c}\text { technical } \\
\text { efficiency } \\
\text { of } \\
\text { financing }\end{array}$ \\
\hline \multirow{2}{*}{$\begin{array}{c}\text { PPP } \\
\text { project }\end{array}$} & Bird Nest & 1.000 & $0.801 \mathrm{drs}$ & 0.801 \\
& QingDao Sewage Treatment Works & 1.000 & 1.000 & 1.000 \\
& Hoijing no. 4 subway & 1.000 & 1.000 & 1.000 \\
& National Grand Theatre & 1.000 & 1.000 & 1.000 \\
\hline \multirow{2}{*}{ Non-PPP } & Thing National Film Museum & 0.444 & $0.434 \mathrm{irs}$ & 0.193 \\
& Whing terminal of Beijing Capital Airport & 0.667 & $0.740 \mathrm{irs}$ & 0.494 \\
& Wukesong Indoor Stadium & 0.694 & $0.961 \mathrm{irs}$ & 0.667 \\
& Shanghai Tower & 0.96 & $0.753 \mathrm{irs}$ & 0.723 \\
& China Central Place & 0.329 & $0.380 \mathrm{irs}$ & 0.125 \\
\hline
\end{tabular}

* drs means decreasing returns to scale; irs means increasing returns to scale

As showed in table 1, in this decision-making unit the pure technical efficiency of financing of four PPP projects is equal to 1, while in six non-PPP projects, it doesn't achieve 1. It obviously illustrates that the four PPP projects compose the efficient frontier hyperplane, reach the pure technical financing efficient point without input redundant and output redundant. By contrast, the pure technical efficiency of financing and the scale efficiency of financing do not achieve the optimal situation in non-PPP projects.

According to the results measured from VRS model, we can see that the relative efficiency of financing of PPP projects is significantly superior to non-PPP projects. It reveals the practical application of the PPP model effectively improves the efficiency of financing in Chinese projects to a certain extent. In addition, it is worth noting that the scale efficiency of financing for the Bird Nest is $0.801 \mathrm{drs}$, that means the financing scale of the Bird Nest is in a decreasing returns to scale status, namely because of its oversize; the input and output of the Bird Nest does not match its financing scale.

It indicates that the Chinese government should further popularize the application and integration of PPP mode in various projects, for it makes considerable improvement in the performance of pure technical efficiency, scale efficiency and technical efficiency of financing in PPP projects. Whilst how does PPP mode impact the financing efficiency and in which input and output it makes the most significant improvement? An understanding of this fact can enable us to know and apply PPP mode better, as well as targetedly increase the efficiency in non-PPP projects. Values of the slack variable and the residual variable derived from VRS model are available to explore this aspect.

For projects which are not up to relatively effective, a quantitatively optimal improvement program can be gained by analyzing the specific VRS model in which the values of the slack variable and the residual variable are decided by the distance between every unit and its projection in the efficient frontier hyperplane. It discloses the input redundancy and the output deficiency of each indicator in every single project. We organize their improve proportion into the following figure 2 . From the distribution of all the indicators, we can intuitively learn the gap between PPP and non-PPP projects. 


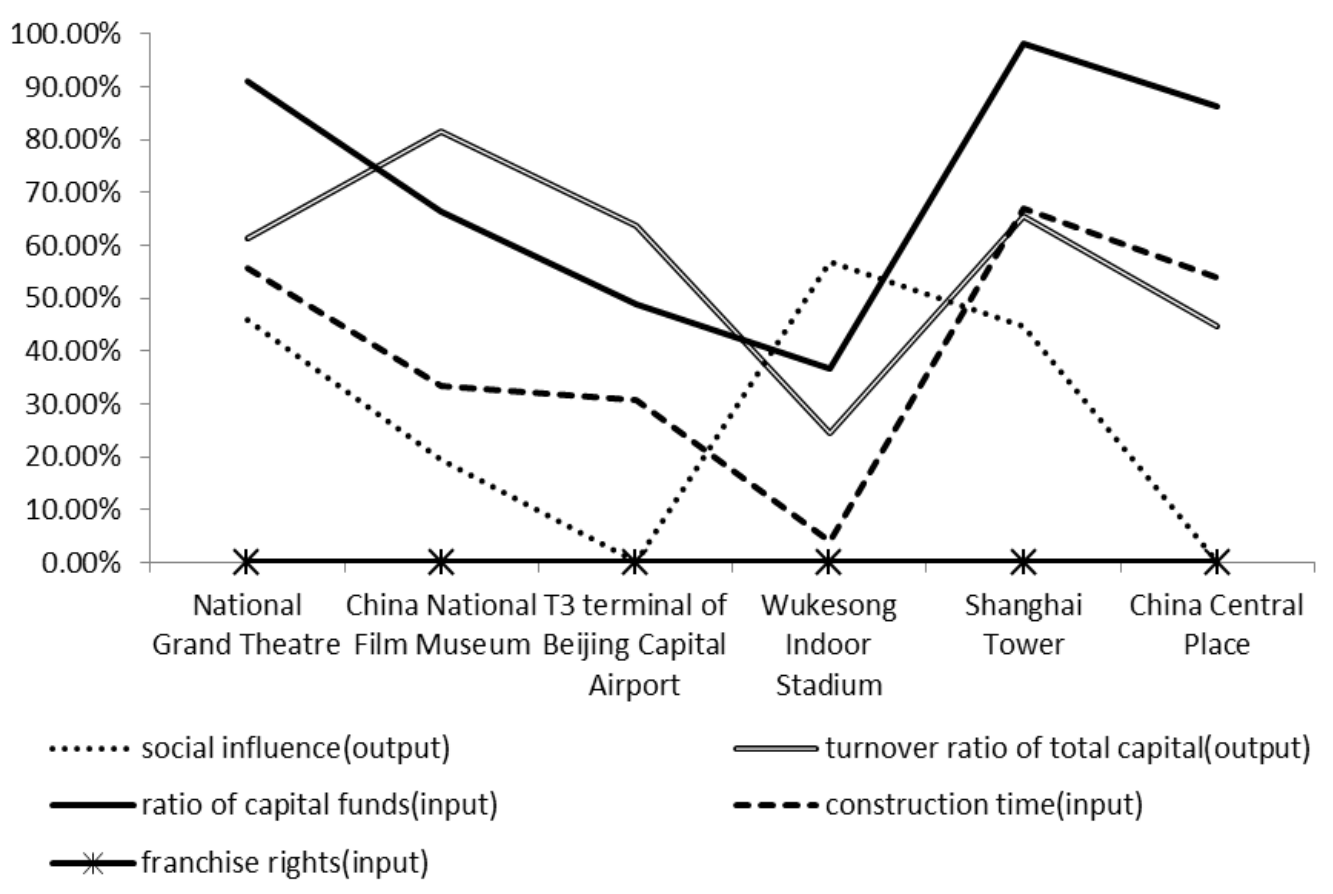

\section{Figure 2. Input Redundancy and Output Deficiency Proportion of Each Index}

Figure 2 clearly shows that compared with PPP projects, input redundancy of capital funds ratio and output deficiency of total capital turnover ratio are two major and common problems affecting the efficiency of financing of non-PPP projects. At the same time, it indicates that the application of the PPP model in China makes a remarkable improvement both in the ratio of capital fund and the turnover ratio of total capital. Hence, the ratio of capital fund and the turnover ratio of total capital are two superiorities of PPP mode, in the future construction of infrastructures, PPP mode is able to offer great help especially in those lack of capital or have stress in cash flow. From another point of view, the ratio of capital fund and the turnover ratio of total capital are two aspects that need improving and perfecting particularly in non-PPP projects.

\subsection{Relative Efficiency of Financing Evaluation for PPP Projects in China Compared with PPP Projects in other Country}

The above case study shows the use of PPP mode improves the efficiency of financing in Chinese projects' construction effectively. While another concern appears, compared with PPP projects in other countries, did its application in China attain the maximum efficiency? In order to study it and guarantee the efficiency distinction ability, four Chinese PPP projects are still used here. Besides, six representative international PPP projects have been selected to compose the new decision-making unit set. Deap2.1 is adopted again to solve the linear programming problem in the VSR model. Similar indicators are obtained here to show the efficiency in three dimensionalities. We arrange the results in the following table 2 


\section{Table 2. The Relative Efficiency of Financing Status of part PPP Projects in} China and Other Counties

\begin{tabular}{clccc}
\hline & \multicolumn{1}{c}{ project name } & $\begin{array}{c}\text { pure } \\
\text { technical } \\
\text { efficiency } \\
\text { of financing }\end{array}$ & $\begin{array}{c}\text { scale } \\
\text { efficiency } \\
\text { of } \\
\text { financing }\end{array}$ & $\begin{array}{c}\text { technical } \\
\text { efficiency } \\
\text { of } \\
\text { financing }\end{array}$ \\
\hline \multirow{2}{*}{$\begin{array}{c}\text { Chinese } \\
\text { PPP project }\end{array}$} & Bird Nest & 1.000 & 1.000 & 1.000 \\
& QingDao Sewage Treatment Works & 1.000 & 1.000 & 1.000 \\
& Beijing no. 4 subway & 1.000 & 1.000 & 1.000 \\
& Hong Kong Disneyland & 1.000 & 1.000 & 1.000 \\
\hline \multirow{2}{*}{$\begin{array}{c}\text { International } \\
\text { PPP project }\end{array}$} & South Africa Ekurhuleni high speed railway & 1.000 & $0.894 \mathrm{irs}$ & 0.894 \\
& Perpignan-Figueras rail link & 1.000 & 1.000 & 1.000 \\
& Sidney Harbour Tunnel & 1.000 & 1.000 & 1.000 \\
& Kamchay Hydropower Station & 0.725 & $0.993 \mathrm{irs}$ & 0.721 \\
& Sidney Olympic Stadium & 1.000 & $0.969 \mathrm{irs}$ & 0.969 \\
& Australia Sewage Treatment Plants. & 0.667 & $0.454 \mathrm{irs}$ & 0.303 \\
\hline
\end{tabular}

* drs means decreasing returns to scale; irs means increasing returns to scale

Judging from all the results presented in table 5.1, we can see in this decision making units set, most of the efficiency of financing of PPP projects have reached relatively effective level, both in China and other countries; in general, the efficiency of financing of PPP projects in China is in a relative higher level, for all the Chinese PPP projects reach pure technical efficiency of financing effective and scale efficiency of financing effective.

Thus, on a global scale, the application of PPP mode in China stands in a relatively efficient position. At the same time, several abroad PPP projects reached the relatively effective level, which warns China that only keep on learning from other countries can it hold on in a favorable position.

\section{Conclusion and Discussions}

This study was motivated to explore the relative efficiency of financing in the application of PPP mode in China. To achieve this goal, a specific VRS model was established to evaluate the relative efficiency of financing in PPP projects, and further applied to study and quantitatively estimate the relative efficiency of financing of PPP projects in China from two perspectives: a) study the effectiveness of PPP mode by comparing PPP projects with non-PPP projects in China, and b) judge the relative application level of PPP mode in China by comparing with PPP projects all over the world.

The study results resolve the puzzle about the relative efficiency of financing from PPP project itself and the relative efficiency of financing of PPP mode application in China.

Firstly, in the decision-making unit composed of Chinese PPP projects and non-PPP projects, all PPP projects are relative financing efficient, while all non-PPP projects are relative financing inefficient. This illustrates that the application of PPP mode significantly improves the relative effectiveness of efficiency of financing in Chinese projects' construction. Sun Fengxuan (2006) draws the same conclusion when he compares PPP with some other financing scheme [17]. While this study further shows that PPP projects have a superior performs especially in the ratio of capital funds and the turnover ratio of total capital.

Secondly, in the decision-making unit composed by Chinese PPP projects and PPP projects in other countries, the pure technical efficiency of financing and scale efficiency of financing of Chinese PPP projects all reach efficient status. It indicates that the applicability and utilization of PPP mode in China are at a relative higher level 
internationally. At the same time, most of the PPP projects in other countries achieve pure technical financing efficient. Such conclusions warn Chinese constructors to keep learning from foreign countries while trying to hold their existing dominance. The same analysis approach can be applied in the efficiency assessment of other countries.

To summarize, this study provide an avenue to explore the relative efficiency of financing in PPP projects, its application in Chinese PPP cases reveals that PPP mode significantly improves the efficiency of financing in infrastructure, especially in in ratio of capital funds and turnover ratio of total capital; and the application of PPP mode in China stands in a relatively effective and superior position all over the world. While this approach is not limited to the study of Chinese cases, it is equally applicable to the study of other countries and regions. It is hoped that this methodology can be helpful in learning the effectiveness of PPP mode and how it effects, further, having a deeper understanding of PPP mode itself and its application objection. This study is potential in supporting quantitative analysis for project design in the project feasibility study stage and summary of projects in the post-project evaluation.

\section{Practical Implication}

In addition to the theoretical implication, this study has some significant practical implications. The approach established in this study is applicable and instrumental to PPP projects itself, stakeholders in PPP projects and government who is the main promoter of PPP. To PPP projects itself, this study offers an avenue to assess its relative efficiency before practical construction and then adjusting the scheme to a better one. To stakeholders in PPP projects, an optimal efficiency of financing plays an important role in running of capital and confirming their future profit. The model of this study helps them to make a better financing plan. From the government perspectives this study assist in having a deeper understanding of PPP, attracting promising investments and knowing their relative level in applying PPP mode.

In order of achieve the more efficient infrastructure constructions in china the current study suggest threefold: Firstly, promotes the application of PPP mode meanwhile establishes standardized mechanism. Secondly, learn from the successful experience of other countries while upholding own superiorities. Last but not least, fully adopt the model given in this study to assess the relative efficiency of financing of PPP projects in the project setting stage and post project evaluation.

\section{Limitation and Future Direction}

Every study has some limitations that can hypothetically affect generalization of the findings. Firstly, this study has geographical limitation associated with just Chinese based PPP projects, future study involves more international projects can generate a more comprehensive and persuasive data of the improvement brought by PPP mode. Secondly, this study has theoretical limitation contained five indicators (ratio of capital funds, time, franchise, social influence and ratio of turnover) in conducting on VRS model, if more indicators can be taken into consideration e.g. (running of capital and risk in raising funds) the result may be a little different.

In the next step of this study, more effort will be devoted to extend this model to study PPP projects in other regions and embracing more international projects to learn the effectiveness of PPP mode. Besides, more dimension of financing efficiency will be deliberated to add in the model, for getting a more comprehensive and exact result. This study provides a base and adds literature for researchers to targets this issue more deeply in the future on other projects. 


\section{Acknowledgement}

The work described in this study was supported by a joint grant from the National Nature Science Fund (70972123) and the National Science Foundation fund (71271031). The authors wish to acknowledge the contributions of Project Management Institution in Beijing University of Posts and Telecommunications, and every team members. Special gratitude is extended to those construction academics and industry practitioners who have responded to and contributed their valuable input to complete the data collect.

\section{References}

[1] A. Akintoye and M. Bec, "Policy, Finance and Management for Public-Private partnership", Blacwell Publishing Ltd, (2009), pp. 33-35

[2] International monetary fund, "The Effects of the Financial Crisis on Public-Private Partnerships", Philippe Burger, (2009), p. 4.

[3] United Nation, "Guidebook on Promoting Good Governance in Public-Private Partnerships: Part I. Setting the Scene", (2008).

[4] Asian development bank, "Public-Private Partnership Operational Plan 2012-2020: IV. Public-Private Partnership Operational and Guiding Principles", (2012), pp. 15-16.

[5] E. R. Yescombe, "Public-Private Partnerships: Principles of Policy and Finance", Elsevier: ButterworthHeinemann, vol. 2, no. 2, (2007), pp. 266-267.

[6] J. D. Finnerty, "Project Financing - Asset-Based Financial Engineering (second edition)", John Wiley\& Sons, Hoboken, (2007).

[7] S. Gatti, "Project Finance in Theory and Practice: Designing, Structuring, and Financing Private and Public Projects (second edition)", Academic Press, San Diego, (2012).

[8] R. Studart, "The Efficiency of Financial Systems, Liberalization, and Economic Development", Journal of Post Keynesian Economics, vol. 18, no. 2, (1995-1996), pp. 269-292,

[9] G. W. E. B. van Herpen, "Public-private Partnerships the Advantages and Disadvantages Examined", Association for European Transport, Cambridge, England, (2002).

[10] Ministry of Singapore, "Public-Private Partnerships Handbook 2012 Vision2: Section 1 Introduction to Public Private Partnerships", Singapore, (2012).

[11] K.-L. Zeng, "How to view direct financing and indirect financing", Journal of Financial Research, vol. 10, (1993), pp. 7-11.

[12] K.-L. Zeng and L. Zeng, "The theory of enterprise financing options", Financial management science, vol. 3, (1996), pp. 35-40.

[13] S.-D. Gan, "Finance of Corporation Financing", Higher Education Press, (2000).

[14] K.-W. Wei, "A financing efficiency compound ambiguous evaluation in small-and-medium-sized enterprise", Journal of Financial Research, vol. 6, (2001), pp. 67-74.

[15] L.-C. Liu, "Efficiency Evaluation on Equity Finance of Listed Companies on Basis of DEA", Systems Engineering, vol. 22, no. 1, (2004), pp. 55-59.

[16] G. Shan, “基于 DEA 方法的科技型中小企业融资效率研究, friend of accounting, vol. 3, (2010), pp. 86-88.

[17] F.-X. Sun, "Study on Financing Models of Urban Rail Transit", degree thesis, Huazhong University of Science and Technology, (2006).

[18] Q.-Z. Liu, "Study on Investment and Financing Efficiency and PPP Application in Liaoning Province Rural Water Infrastructure", degree thesis, Shenyang Jianzhu University, (2012).

[19] P. F. Wanke, "Public-private partnerships and scale efficiency in Brazilian ports: Evidence from twostage DEA analysis", Socio-Economic Planning Sciences, vol. 51, (2015), pp. 13-22.

[20] L. Qining, "Introduction to Decision Analysis", Tsinghua University Press, Beijing, (2013).

[21] T. Sueyoshi and Y. Yuan, "Comparison among U.S. industrial sectors by DEA environmental assessment: Equipped with analytical capability to handle zero or negative in production factors", Energy Economics, vol. 52, Part A, (2015), pp. 69-86,

[22] B. Wu, Y. Wang and J.-F. Zhang, "Effectiveness of maritime safety control in different navigation zones using a spatial sequential DEA model: Yangtze River case”, Accident Analysis \& Prevention, vol. 81, (2015), pp. 232-242.

[23] R. D. Banker, A. Charnes, and W. W. Cooper. "Some Models for Estimating Technical and Scale Inefficiencies in Data Envelopment Analysis", Management Science, vol.9, (1984), pp. 1078 - 1092

[24] R. K. Jain and R. Natarajan, "Corrected Proof - Note to users, A DEA study of airlines in India", Asia Pacific Management Review, Available online 25 June, In Press, (2015).

[25] M. J. Farrell, "The measurement of productive efficiency", Journal of the Royal Statistical Society, Series A(General), vol. 120, no. 3, (1957), pp. 253-290.

[26] Y.-H. Shai, Y.-X. Huang and A.-F. Xin, Engineering Economics, Tongji University Press, Shanghai, (2013). 
[27] D. Qi, Z. Feng, T.-H. Yang and C.-L. Wang, "Efficiency assessment model of the depot of resource allocation based on DEA", Wavelet Active Media Technology and Information Processing (ICWAMTIP), International Conference, (2012); Sichuang, China.

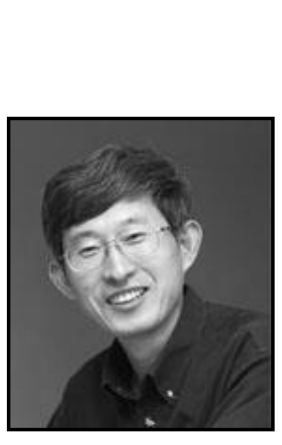

\section{Authors}

Wang Chang Feng, is the director of the International Project Management Institute in Beijing University of Posts and Telecommunications, professor and Ph.D. supervisor. He is an expert in guiding the PMI GAC project management accreditation, assessment expert for PMI GAC CRC project management accreditation. His main research areas include the enterprise project management of safety risk warning and emergency response, and the complex system integration and control of major projects and programs.

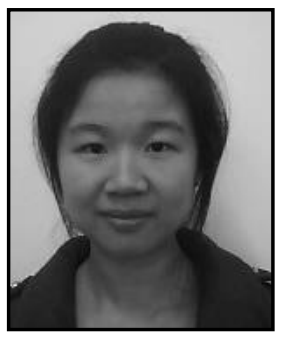

Qiu yixin, is a master scholar at Beijing University of Posts and Telecommunications, Beijing China. She received bachelor's degree in management science from Jiangxi University of Science and technology. During her study, she got honors in China Undergraduate Mathematical Contest in Modeling (CUMCM), and the National College English Contest (NECCS). Her current research interest is project management in PPP projects.

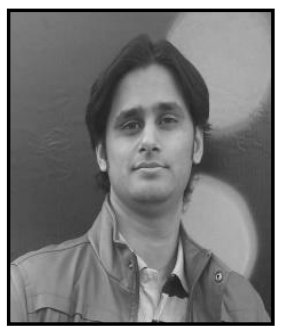

Umair Akram, is a PhD Scholar at Beijing University of Posts and Telecommunications, Beijing China. Before commencing his Doctoral research, he worked as a Lecturer. He holds post-graduation in Business Administration. His areas of interest include Consumer Behavior, E Marketing and Advertising.

Corresponding Author: leo_umairinfo@yahoo.com

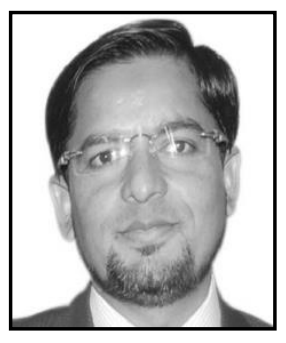

Shahid Rasheed, is a Ph.D. researcher at Beijing University of Posts and Telecommunications, China. He has been engaged in the telecommunications, defense and other engineering sectors since 1998. Before commencing his doctoral research, he worked as Senior Manager at Pakistan Telecommunication Company Ltd. (Etisalat); mainly in the projects and strategic management functions. He holds post-graduation qualifications in Business Administration as well as Telecom Engineering fields. His areas of interest include Program and Strategy Management, ICT developments and allied disciplines. 